\title{
ESTUDIOS
}

\section{Una Posible Fuente Española del Fausto de Estanislao del Campo}

$\mathrm{H}$ AsTa no hace mucho tiempo la crítica prefería ver en la poesía gauchesca argentina un producto cultural casi espontáneo, sin vinculación alguna con las literaturas europeas. Hoy sabemos que esa poesía, que se desarrolla en nuestro país durante el siglo XIX, presenta muchos rasgos del costumbrismo romántico y de la literatura regionalista española. Suele citarse a Miguel de Unamuno como el primero en indicar relaciones entre la poesía gauchesca y poemas españoles. ${ }^{1}$ Nadie se asombra ya al comprobar como fuente directa de los "Consejos del viejo Vizcacha" en el Martín Fierro, por ejemplo, los que el tío Lucas de Espronceda prodiga en el Diablo Mundo con la misma incredulidad del gaucho ante los valores absolutos y abstractos, la misma moralidad utilitaria, idénticos juegos expresivos y hasta refranes similares. ${ }^{2} \mathrm{El}$ pro-

1 Miguel de Unamuno. "El gaucho Martín Fierro. Poema popular gauchesco de D. José Hernández", La Revista Española, Madrid, 1894. Por esta misma fecha, y quizá con antelación, don Ricardo Monner Sans había parangonado la poesía gauchesca con la popular española en conferencia pronunciada el 9 de julio de 1894 en la ciudad de Adrogué y recogida en su libro Desvestirse, publicado ese año.

2 Las similitudes evidentes entre los "Consejus del viejo Vizcaya" y el episodio del Diablo Mundo de Espronceda han sido señaladas por varios críticos. Creo que es el primero de ellos Federico de Onís en su estudio "El Martin Fierro y la presía tradicional", Homenaje a Menéndez Pidal, 1924. Ezequiel Martínez Estrada, en Muerte y transfiguración del Martín Fierro, 2: tomo, Buenos Aires-México, Fondo de Cultura Económica, 1948 (2* edición, corregida, 1958), cita y utiliza la con. 
fesor Julio C. Caillet-Bois, al referirse a las páginas de Hilario Ascasubi, o Aniceto el Gallo, que preceden a Los mellizos de la flor, dice justamente: "Nuestro relato pertenece, pues, a esa vasta literatura vulgar cuyos antecedentes españoles son los libros de cordel en prosa. . . y cuyo modelo contemporáneo es la novela por entregas que en la segunda mitad del siglo $\mathrm{xIx}$ prolongaba la narración romantica de tema bistórico". ${ }^{3}$ No extraña esa relación, cuando hasta la misma poesía tradicional, popular y anónima, recoge frecuentemente temas, fragmentos y hasta poemas íntegros de poetas románticos o postrománticos. ${ }^{4}$

Pero no son los poemas gauchescos, obvio es aclararlo, poemas de indole española, como excesivamente lo entendía Unamuno. Su originalidad, como la de toda auténtica poesía, reside en zonas más profundas del espiritu que las que rozan circunstanciales temas o contactos literarios.

En una novela del siglo xIx, importante en la historia de la novelística española, La Gaviota de Fernán Caballero (Cecilia Böhl de Faber) encontramos 5 un relato cuyas características recuerdan muy estrechamente al poema gauchesco Fausto del poeta argentino Estanislao del Campo y a la Carta de Anastasio el Pollo sobre el beneficio de la señora de la Gria, que su descubridor, Angel J. Battistessa, estudió como una prefiguración del poema. ${ }^{6}$ Ambas composiciones tratan un asunto parecido: un

siderable bibliografía sobre el tema. Léase Angel Héctor Azeves, La elaboración literaria del Martin Fierro (La Plata: Facultad de Humanidades, 1960).

3 Julio C. Caillet-Bois. "Introducción a la poesía gauchesca. Hilario Ascasubi", en Historia de la Literatura Argentina, tomo III (Buenos Aires: Peuser, 1959 ), p. 1. [El subrayado es mío].

4 No es el caso de citar aquí los cancioneros americanos que aparecen frecuentemente ejemplos de estos contactos. Recuerdo que cuando niños cantábamos como tema popular colombiano la poesía "Si dos con el alma - se amaron en vida", de la romántica española Caro'ina Coronado. Entre las coplas y cantares de Antonio de Trueba, publicados en $E l$ libro de los cantares (Leipzig: F. A. Brockhaus, 1874) hallo una copla que se repite en una canción popular argentina: "Llora, llora corazón - Ilora si tienes por qué - que no es delito en el hombre - llorar por una mujer". Sobre la difusión de Trueba y otras relaciones de sus poesías con la poesía tradicional americana, véase el útil prólogo del $\mathbf{P}$. Alfonso M. Escudero, en Antonio de Trueba, Cuentos y cantares (Madrid: Aguilar, 1959).

5 Valga el plural. El profesor Alfredo A. Roggia:o señaló ya esta fuente en "Un posible antecedente del Fausto de Estanislao del Campo", en Ovaciones, México, $N^{\circ} 43$, del 21 de octubre de 1962. No he visto el artículo, pero transcribo un párrafo de la comunicación que el profesor Roggiano me hace desde la Universidad de Pittsburgh, Pennsylvania: "Se trata de una nota en donde aludo al episodio de La Gaviota, brevemente, como posible antecedente del episodio similar que sirve de asunto al Fausto".

6 Ver Angel J. Battistessa, "Génesis periodística del Fausto", en Anales del Instituto Popular de Conferencias, año 1941, Buenos Aires, 1942, tomo XXVI: del mismo autor, Fausto, edición crítica (Buenos Aires: Peuser. 1951). Reproduce el poema, comparándolo con el Fausto definitivo, Rafael Alberto Arrieta en su estudio "Estanislao del Campo", Historia de la Literatura Argentina, ya citada. 
gaucho relata la representación de una ópera que ha visto y escuchado en la ciudad. En un episodio de La Gaviota, un rústico narra a su madre y a su abuela la representación también de una ópera vista durante su estancia en Madrid. Por las fechas, es posible que Del Campo haya podido conocer el episodio antes de la composición de la Carta, y lo haya tenido en cuenta durante la redacción del Fausto.

El Fusto fue escrito hacia mediados de r866. En septiembre de ese año aparece en el Correo del Domingo de Buenos Aires. En I870 integra el cuerpo de las Poesictis del autor en un solo volumen. La Carta de Anzastasio el Pollo sobre el beneficio de la señora de la Gría fue compuesta pocos días antes de su aparición en Los Debates de Buenos Aires, en agosto de $1857 .^{7}$

Desde 1857 y hasta 1866 parece Del Campo preocupado por la idea de narrar una representación teatral vista por un gaucho. Hacia principios de 1862 puede fecharse otra carta en verso que dirige a Aniceto el Gallo con motivo de la partida de éste hacia Europa. Aunque no se refiere al mismo asunto, advertimos en ella una parecida contraposición entre la vida campesina y la de ciudad, con similar tratamiento, el mismo sentido del humor, y hasta versos idénticos a los del Fausto. ${ }^{\mathrm{B}}$

7 Ver Rafael Alberto Arrieta, op. cit.

8 Decimcs que esa Carta (ver Poesía gauchesca, prólogo, notas y glosario de Jorge Luis Borges y Adolfo Bioy Casares, tomo II, México-Buenns Aires, Fondo de Cultura Económica, 1955) puede fecharse hacia principios de 1862. por las concretas referencias que en ella se hacen a la situación política de Méxio:

$$
\begin{aligned}
& \text { Y que va los mejicanos } \\
& \text { se han basuriao a un tal Prin. } \\
& \text { Dicen que la gallegada } \\
& \text { que acampó por Vera Cruz, } \\
& \text { ni bien bañó con su luz } \\
& \text { el campo, la madrugada, } \\
& \text { sin aguardar, la gringada } \\
& \text { campo adentro se metiớ; } \\
& \text { v que ni bien la sintió } \\
& \text { la milicada de Juárez } \\
& \text { le cayó con los dos pares } \\
& \text { y ahí mesmo la redotó. }
\end{aligned}
$$

El encuentro del general Prim con las trnpas de Juárez en Veracruz se produjo el 17 de diciembre de 1861 . La Carta debe haber sido escrita semanas después, calculando la demora habitual entonces en la llegada de noticias.

En esa Carta, el autor, tras hacer emisario a su amigo de festivos recados para los españoles, franceses e ingleses comprometidos en la contienda, y luero de expresar en versos rotundos su sentido americanista, aconseja a Aniceto el Gallo 
Un año antes de la composición de la Carta de Anastasio el Pollo sobre el benificio de la señora de la Gría, es decir, en 1856 , aparecen los dos tomos primeros de las Obras completas de Fernán Caballero, uno de los cuales incluye La Gaviota. No creo posible que en el transcurso de un año haya podido Del Campo conocer esa edición antes de la Carta. Pero La Gaviota, que había sido escrita primeramente en francés y traducida luego al español por José Joaquín de Mora, ${ }^{9}$ fue conocida y aplaudida en Madrid a través de su publicación como folletín de El Heraldo en el verano de 1849. Eugenio de Ochoa contribuyó a la difusión del folletín con su poco medido elogio al comparar a Fernán Caballero con Walter Scott.

Entre 1849 , fecha del folletín, y 1856 , fecha de las Obras completas, pudieron existir otras ediciones de La Gaviota. La enorme popularidad de la autora, su renombre en Francia y en Alemania, países conde se la tradujo y ecitó indiscriminadamente, debieron sin duda tentar a los edi-

el comportamiento que corresponde a un gaucho en Europa. Allí, dice festivamente:

$$
\begin{aligned}
& \text { Algunos train de un cordón } \\
& \text { dos vidriecitos colgaos } \\
& \text { por parecer delicaos } \\
& \text { de la vista, cuando, amigo, } \\
& \text { ven a cien leguas un higo } \\
& \text { sus ojcs despabilados. }
\end{aligned}
$$

La doma con "clorofor" (cloroformo), las carreras en hipódromos: "ellos dan güeltas enteras... en un circo como un tejo"; la vestimenta de jinetes y caballos "en apero de dotor"; todos los detalles anticipan la gracia fresca del Fausto.

Más aún, al pedir al amigo que regrese tal cual se va, del Campo afima que Aniceto no le hará "partida tan fea".

$$
\begin{aligned}
& \text { sólo porque usté hava andao } \\
& \text { mirando medio abombao } \\
& \text { la fantasía europea. }
\end{aligned}
$$

La fantasía europea, o la fantasía de Buenos Aires. que mira hacia Europa, aparecerá representada simbólicamente cuatro años después en un teatro porteño. Si se duda de ella, veamos estos versos anticipados del Fausto que describen en la Carta el cabello de los europeos:

$$
\begin{aligned}
& \text { Ese pelo cclcrao } \\
& \text { que ahuyenta a cualquier muchacha, } \\
& \text { y que parece esa hilacha } \\
& \text { del choclo recien cortao. }
\end{aligned}
$$

9 Entre otros, Vicente Llorens Castillo se ha ocupado de esta interesante figura en Liberales y románticos. Una emigración española en Inglaterra (1823. 1834), publicado en 1954. No hay iniciativa política o literaria durante su tiempo en que no aparezca mezclado el nombre de Mora. Mora anduvo por la República Argentina hacia 1826 y fue autor bastante leído de nuestro país. Del Campo cita un fragmento de una poesía de Mora en su poema festivo "Mi nariz", colocándolo como epígrafe. Puede verse el poema en la edición citada de sus Poesías. 
tores. En ese momento comenzaba a pensarse en los lectores hispanoamericanos. Se ha supuesto la existencia de una edición clandestina de Nueva York, año I850; una editorial norteamericana, La Crónica, publica en esa fecha otra novela de Fernán Caballero, La familia de Alvarelda, sin autorización de la autora. Al referirse a esa edición, dice José F. Montesinos en una nota bibliográfica: "Parece ser que estas gentes de La Crónica piratearon también La Gaviota y La suegra del diablo, con otras muchas cosas de procedencia hispánica; pero la nota de Hespelt, ${ }^{10}$ poco clara, no permite deducir cómo salió todo ello; si en un solo volumen, éste debe ser in quarto muy mayor. Hespelt no dice dónde hay ejemplar y yo no he podido verlo".'11 El texto de La Gaviota para esa edición pudo ser tomado, como lo fue el de La familia de Alvareda, directamente de $\mathrm{El}$ Heraldo.

No es tarea fácil rastrear esas ediciones clandestinas, tan frecuentes en América. La casa editorial Brockhaus, de Leipzig, inundó el mercado latinoamericano con ediciones de ese tipo. En lo que respecta a Fernán Caballero, las ediciones de Brockhaus no parecen anteriores a I860; por esa misma fecha el mismo sello difundía ya las obras de Antonio de Trueba. Ignoramos por qué esa preferencia del consejero editorial de la casa Brockhaus por escritores tradicionalistas; probablemente esos autores satisfacian más al público hispanoamericano que vivía frente a problemas semejantes: la oposición falsa entre tradición y progreso, la defensa de la vida de aldea en menosprecio de la vida ciudadana, el debate político entre un liberalismo europeizante y un tradicionalismo popular, autocrático y cristiano.

Cualquiera de esas ediciones pudo ser conocida por Del Campo antes de la redacción del Fausto; si excluimos a la de Brockhaus, las restantes pudieron también ser conocidas por él antes ce la composición de la Carta de 1857 .

Por otra parte, Estanislao del Campo era un hombre de curiosas lecturas. Gusta del teatro, acostumbra colocar como epígrafes de sis poesías trozos de autores franceses, españoles o americanos, no oculta reminiscencias muy directas de poetas románticos como Espronceda. Ricardo Rojas relaciona el nombre de Quevedo con uno de sus poemas. ${ }^{12}$

10 Se refiere Montesinos, según él mismo aclara, a un artículo aparecido en Modern Languages Notes. XLI, 1926, pp. 123-125.

11 José F. Montesinos, Fernán Caballero, ensayo de justificación (México; El Colegio de México, 1961).

12 Ver Ricardo Rojas, "Los gauchescos", tomo II, Historia de la Literatura Argentina, Buenos Aires: La Facultad, 1924). 
En la carta de despedida a Aniceto el Gallo con motivo del viaje de éste a Europa, recubre Del Campo galanamente la alusión a la hermosa voz de la hija de su amigo con una reminiscencia desdibujada de la Odisea de Homero. ${ }^{13} \mathrm{Y}$ se trata de un poema gauchesco. Su propio Fatusto, y ello debió incidir en la decisión de Hernández de escribir un poema će auténtica indole gauchesca, ${ }^{14}$ es -no lo olvidemos- la relación que hace un hombre de ciudad complaciéndose en oponer el mundo culto de Buenos Aires a la incultura del gauchaje. En los parlamentos, las alusiones, las demoradas descripciones poéticas, las reflexiones entre sentimentales y filosóficas, que Del Campo prodiga en su poema, muestra una cultura literaria desconocica por los restantes poetas gauchescos. ¿Podría ignorar la obra de Fernán Caballero, ya difundida por América? ¿Ignoraría a una novelista que partiendo de la narración romántica, como la misma poesia gauchesca, llega al realismo a fuerza de pintar con verdad, según la estética romántica lo exigía, la real psicología del rústico y su lenguaje?

III

Rafael Alberto Arrieta analiza en el estudio ya citado la estructura del Fcursto. Distingue el episodio central de agregados cuyo "borde sutil" denuncia la soldadura. Son esos agregados la escolarizada descripción de la mañana y las reflexiones sobre el amor y la mujer. Prescindiendo de esas partes, el asunto fundamental del poema es el siguiente:

Un paisano cuenta a su aparceto la representación de la ópera Fausto de Gounod, cantada en el teatro Colón de Buenos Aires en I866. Se narra

$$
\begin{aligned}
& \text { Abra el ojo por la mar } \\
& \text { y es güeno que le aconseje } \\
& \text { que a su hijita no la deje, } \\
& \text { ni por asomo cantar; } \\
& \text { pues si la llega a escuchar } \\
& \text { una envidiosa sirena, } \\
& \text { afirmándose en la arena } \\
& \text { le puede el barco cociar } \\
& \text { y yo no quiero llorar } \\
& \text { de esa pérdida la pena. }
\end{aligned}
$$

14 La parodia del habla y de la psicología gauchesca en Hidalgo, Ascasubi y del Campo motiva la crítica de Hernández: "Quizá la empresa habría sido para mí más fácil y de mejor éxito, si sólo me hubiera propuesto hacer reír a costa de su ignorancia [del gaucho] como se halla autorizado por el uso en este género de composiciones" dice José Hernández refiriéndose al carácter distinto del Martín Fierro en la carta a D. José Zoilo Miguens, recogida en la citada edición de Borges y Biov Casares, p. 576. 
desde la compra del billete de entrada hasta el cietre final del telón. El gaucho describe al público que sube por las galerías, cuenta la pérdida o posible robo del facón, y apenas se detiene en pintar el teatro y los preliminares de la función. Al terminar cada acto, el paisano interrumpe su relato para beber un trago con su interlocutor. En esos largos intermedios, mecha Del Campo consideraciones externas a la representación ("¿Sabe que es linda la mar?...") o acerca de la representación ("Pobre rubia, vea Vd...") que son poemas unitarios anudados hábilmente al relato.

El paisano confunde su realidad con la fantasía escénica. No entiende la urdimbre teatral. Reduce las leyes de la casualidad artística a las de la casualidad de la vida real. Como el diablo es en el Fausto un personaje concreto, todo aquello que la lógica cotidiana no explique, lo explicará la diabólica magia. El miedo de lo inexplicable, el asombro ante lo pintoresco, la compasión por el cestino de Margarita, que el gaucho sintió cuando espectador, se convierten cuando narra en interjecciones, comentarios y gestos.

La poesía gauchesca en sus primeras manifestaciones remeda a la poesía oral y como ella apela a un público. En la Carta indicada como antecedente del Fausto, el gaucho se dirige al público. Del Campo, en el Fausto, a pesar de tratarse de una parodia literaria, respeta esa tradición y personifica al público en Laguna. Este paisano convive con el narrador la emoción del relato. Metido en la misma atmósfera alucinante del narrador, lo apura o lo detiene, comenta los detalles sorpresivos, produce, en fin, incidencias sabrosas.

En forma indirecta, la oposición ciudad-campo asoma a cada instante en la confrontación reiterada entre la vida pueblerina y la ingenua psicología del gaucho.

La Carta de Anastasio el Pollo sobre el beneficio de la señora de la Grúa es una relación también en verso. El asunto central es similar al del Fausto. Un gaucho relata la representación, vista en un viaje circunstancial a Buenos Aires, de la ópera Saffo de Giovanni Paccini. El gaucho expresa su asombro ante los nuevos o modernizados edificios porteños. Cuenta la llegada casual al teatro en cuya puerta se anuncia el beneficio. Esta introducción y otras peripecias ocupan la mayor parte del poema. En sólo seis estrofas se condensa el asunto de la representación misma. Faón -explica Battistessa-celebra su himeneo con la rival de Safo, cuando ésta entra de improviso y voltea el altar sagrado. Debe ser castigada por ese sacrilegio. Safo canta sus desdichas y se arroja al mar desde la cima 
del Leucade. En el momento en que baja definitivamente el telón, el paicano espectador está disponiéndose a salvar a la suicida. La Carta carece de valores literarios, evidencia falta de economía y fallas en la composición. No alcanza las excelencias del Fautsto, ni su travieso espíritu, pero adelanta algunos elementos humorísticos que Del Campo repetirá en el poema definitivo.

En el capítulo XVI de La Gaviota, Momo, feo y apicarado joven campesino, cuenta a su madre y a su abuela la representación de la ópera Otelo de Rossini que ha visto en Madrid. El relato se destaca suficientemente del resto de la novela. Parecería una relación de origen popular insertada, al modo de los cuentos que se atribuyen al mismo Momo a lo largo de la obra.

Para obviar dificultades de interpretación y evitar citas enojosas, me parece prudente transcribir el relato:

Cuando llegué a Madrid - dijo Momo-y me vi solo en aquel cotarro, se me abrieron las carnes. Cada calle me parecía un soldado; cada plaza, una patrulla. Con la papeleta que me dio el Comandante, que era un papel que hablaba, fui a dar en una taberna, donde topé con un achispado, amigo de complacer, que me llevó a la casa que rezaba el papel. . Pues señor, el criado se puso el sombrero y me llevó a una casa muy grandísima y muy alta, que era a moo de iglesia; sólo que en lugar de cirios tenía unas lámparas que alumbraban como soles. En rededor había como unos asientos, en que estaban sentadas, más tiesas que husos, más de diez mil mujeres, puestas en feria, como redomas en botica. Abajo había tanto hombre que parecía un hormiguero... ¡Cristianos! Yo no sé de dónde salió tanta criatura. Pues no es nada, dije para mi chaleco, ¡las hogazas de pan que se amasarán en la villa de Madrid!. . .

Pues cate usted ahí, que de repente, y sin que nadie se lo mandase, suenan a la par más de mil instrumentos, trompetas, pitos y unos violines tamaños como confesionarios, que se tocaban para abajo. ¡María Santísima, y qué atolondro! Yo di una encoginada, que fue floja en gracia de Dios...

Pero no es esto lo mejor; sino que cate usted ahí, que sin saber ni cómo ni por dónde, desaparece un a moo de jardín que había al frente. No parecía sino que el demonio había cargado con él.

- ¿Qué estás diciendo, Momo?- dijo Dolores. 
- Naíta mas que la purísima verdad. En lugar de la arboleda había al frente una moo de estrado, con redondeles de trapo, que sería de un palacio. Allí se presenta una mujer más ajicalada, con más terciopelos, bordaduras de oro y más dijes que la Virgen del Rosario.

-Esta es la Reina doña Isabel Segunda - dije yo para mi chaleco. - Pues no, señor, no era la Reina. ¿Saben ustedes quién era? ¡Ni más ni menos que la Gaviota, la malvada Gaviota, que andaba aquí descalza de pies y piernas! Lo primero que sucedió con el vergel había sucedido con ella; la Gaviota, descalza de pies y piernas, se la habia llevado el demonio, y en su lugar había puesto una principesa. Yo estaba cuajado. Cuando menos se pensaba, entra un señor mayor muy engalanado. Estaba que echaba bombas. ¿Qué enojado! Ponía unos ojos... ;Caramba! - dije yo para mi chaleco. -No quisiera yo estar en el pellejo de esa Gaviota. A todo esto, lo que me tenía parado era que reñ'an cantando. ¡Vaya! Será la moa por allá, entre la gente de fuste. Pero con eso no me enteraba yo bien de lo que platicaban: lo que vine a sacar en limpio fue que aquél sería el general de don Carlos, porque ella le decía padre,,$^{15}$ pero él no la quería reconocer por hija, por más que ella se lo pidió de rodillas.

- ¡Bien hecho! - le grité; - duro a la embustera descarada.

- ¿A qué te metiste en eso? - le dijo su abuela.

- Toma! Como que yo la conocía y podía atestiguarlo. ¿No sabe usted que quien calla otorga?..

...Cuando volvimos a entrar es de presumir que le habría mandado el general a la Gaviota que se quitase los arrumacos, porque salió toda vestida de blanco que parecía amortajada. Se puso a cantar, y sacó una guitarra muy grande que puso en el suelo y tocó con las dos manos (iy qué no es capaz de inventar esa Gaviota!); y ahora viene lo gordo, pues de repente sale un moro.

- ¿Un moro?

- iPero qué moro! Más negro y más feróstico que el mismisimo Mahoma; con un puñal en la mano, tamaño como un machete... ¡Yo me quedé yerto!

-iJesús María!-exclamaron su madre y su abuela.

\footnotetext{
,15 Los criados de la Graviota han referido a Momo que María, ocultando su origen, se ha inventado como supuesto padre a un general carlista. Es ésta la causa de la confusión de Momo.
} 
-Pregunté a Nicolás que quién era aquel fierabrás y mè respondió que se llamaba Telo. Para acabar presto; el moro le dijo a la Gaviota que la venía a matar.

- Virgen del Carmen! -exclamó la tía María. - Era acaso el verdugo?

-No sé si era el verdugo, ni sé si era un matador pagado -respondió Momo. - Lo que sí sé es que la agarró de los cabellos y la dio de puñaladas: lo vi con estos ojos que ha de comer la tierra y puedo dar testimonio...

Las dos buenas mujeres lanzaron un grito. La tía María sollozaba y se retorcía las manos de dolor.

- ¿Pero qué hicieron tantos como presentes estaban? -respondió Dolores llorando. - ¿No hubo nadie que prendiese a ese desalmado?

-Eso es lo que yo no sé-contestó Momo. - Pues al ver aquello, cogí dos de luz y cuatro de traspón, no fuese que me llamasen a declarar, y no paré de correr hasta no poner algunas leguas entre la villa de Madrid y el hijo de mi padre.16

Cuando María, al final de la novela, regresa a su alclea, perdida su honra, su fama y su voz, y vuelve a ser la Gaviota, soez y rústica, increpa a Momo de esta manera:

¿Y quién tuvo la culpa, malvado ganso? Nada de eso habría sucedido si no hubieras sido tú un salvaje, que te volviste de Madrid, sin haber desempeñado tu encargo, y esparciendo la nueva de mi muerte... Solamente en sus entendederas, que son tan romas como tus narices, cabe el haber creido que una representación era una realidad.

El relato de Momo, que hemos transcripto casi totalmente, queda en la memoria del lector como uno de los momentos más logrados de la novela de Fernán Caballero. En ese personaje, como solía hacerlo con los secundarios, la autora puso toda la vida de la creación. Debía ser ella consciente de la riqueza de su criatura, pues en 1865 , ya muy difundida la novela, Fernán Caballero recuerda a Momo ante una crítica desfavo-

16 Utilizo para esta transcripción y las siguientes, la edición hecha para los Estados Unidos por George W. Humprey y F. Sánchez Escribano, y publicada por D. C. Heath and Company en Boston, etc., en el año 1930. 
rables de don Juan Valera y reproduce entonces el adjetivo que aplica Momo a la Gaviota: "La muldita Gaviota, que ya voy aborreciendo tanto conno lo hacía Momo". 17

El nombre de la novela de Fernán Caballero proviens, como se recordará, del sobrenombre que Momo da a María, la hija del pescador. La llama la Gaviota "porque tiene las piernas muy largas, porque tanto vive en el agua como en la tierra, porque canta y grita y salta de roca en roca como las otras". Del Campo, en la Carta de Anastasio el Pollo sobre el beneficio de la señora de la Gría, pone en boca del paisano la palabra "grulla" o "gruya" como deformación del nombre de la cantante. La grulla es también un ave de largas patas y de costumbres acuáticas. ${ }^{18}$ La señora De la Grúa y la Gaviota tienen además la similitud de ser ambas afamadas cantantes de ópera.

Si comparamos detalladamente la Carta con el relato de Mono encontraremos muchos otros puntos de contacto. En notas iremos indicando los elementos que pasan luego al Fousto definitivo:

A) El paisano en la ciudad: La narración de Momo se inicia con una rápida consideración sobre lo sucedido a su arribo en Madrid. Momo ha sido enviado a la ciuclad con un encargo ce terceros: avisar a María y a su marido que el padre de la joven agoniza. También por encargo de terceros, en este caso "Ño Anacleto", Anastasio va a la ciudad, según la Caral, para buscar un "certificado de marcación". ${ }^{19}$

Fernán Caballero alude, por intermedio de Momo, al estado de Madrid en 1836 , llenas sus calles de solciados con motivo de las guerras carlistas. En la Corta, Anastasio se refiere a Buenos Aires, con la Aduana nueva y el gran Coliseo, una terminada de construir hacia 1857 y el otro inaugurado hacia principios de ese año. ${ }^{20}$

La actitud de Mono en la ciudad es de temor; la de Anastasio, de

17 Según referencia de Montesinos, op. cit.

.18 En la Vuelta de Martín Fierro, canto XVII, el hijo mayor dice que Vizcacha. ante la arremetida de Barullo, "apeló a las de gaviota" huyendo del entrevero.

19 En el Fausto, Anastasio va a la ciudad por motivos personales: "ver si cobro una lana".

20 En el Fausto, Del Campo prefiere aludir a la situación moral de la ciudad: "gringos que no pagan sus deudas", "cuento de la guerra" (del Paraguay), "la pobreza del criollo". 
asombro. Los dos acuden al auxilio de forasteros para compensar su desconocimiento del lugar. Son esos forasteros un "achispaco" en el caso de Momo, un vigilante y un naranjero en el caso de Anastasio, en la Carta. En ambos relatos, el motivo del vino aparece vinculado a los desconocidos. Momo encuentra al ciudadano "achispado"; Anastasio invita al vigilante a beber "giñebra, aguardiente y vino". Cuando Nicolás, criado de la Gaviota, saca a Momo antes de terminar el acto, van ambos a "echar un trago".21

B) El teatro: En La Gaviota, Momo atiende, en la descripción del teatro, a la magnitud cel edificio y al gran número de luces en la sala. Lo llama "una casa muy grandísima y muy alta" y la compara con otro gran edificio que conoce: la iglesia. Es también la grandiosidad del edificio lo primero que sorprende a Anastasio en la Carta. Lo llama "caserón", aludiendo a una casa grande, o "galpón" comparándolo con otro recinto de parecida amplitud.

Ambos, Momo y Anastasio, expresan de inmediato su asombro por las luces del salón. Para Momo, las lámparas "alumbraban como soles" Anastasio también compara las luces con el sol:

Del techo de aquel galpón

vice colgando una cosa

que por grande y relumbrosa

sol se me hizo en la ocasión.

C) El público: Sin transición, Momo describe la muchedumbre de espectadores. Ve la platea desde el gallinero. En los palcos, están las mujeres, ${ }^{22}$ y abajo, "como hormigueros", los hombres. Le extraña la distribución en hileras y gradas. Compara ese ordenamiento con realidades de su vida cotidiana: la colocación de mercaderías en las ferias, 3 ce los frascos en las estanterías de las boticas. Del mismo modo procede Anastasio. Ve a la platea también desde "lo último que había" y compara al público así ordenado con "altillos", "estibas" o "camadas", términos muy usados en las tareas del agro:

2I El vino corre en el Fatusto con la misma facilidad que la narración. Entre acto $\mathrm{y}$ acto, los paisanos -como Momo- "echan un trago".

22 En la citada edición de Humprey y Sánchez Escribano, encuentro esta nota suficicntemente aclaratoria: "With regard to his description of the audience, it should be noted that until quite recently women were not admitted to the lower floor of a Madrid theater, one of the galleries being reserved for them". 
Cuando yo me serené
vide puros altillitos
llenos de gente toditos
a la que yo saludé,
en seguida me afigé
que otras hileras había
de hombres y mujería
rigularmente estivada
y al último otra camada
que apenas se distinguía. ${ }^{23}$

D) Orquesta. Telón. Decorados: En los dos relatos, la descripción del comienzo del espectáculo se reduce a algunas pocas notas fundamentales: la irrupción de la orquesta, el levantamiento del telón y la descripción de los decorados.

Momo enfatiza el inesperado y súbito comienzo de la música: "De repente y sin que nadie se lo mandáse, suenan a la par más de mil instrumentos". También Anastasio se detiene en el comienzo sorpresivo de la música:

\section{Cuando de golpe y zumbido una música sonó ... ${ }^{24}$}

El mismo efecto sorpresivo provoca en los dos relatores el levantamiento del telón. Para Momo "sin saber ni cómo ni por dónde desaparecen un a moo de jardín que había al frente. No parecía sino que el demonio había cargado con él". Sobre este párrafo y la alusión al demonio volveremos más adelante.

No está ausente el demonio en la descripción de Anastasio, en la Corta. El gaucho ha transferido, con un esguince que le evita confesar

23 En el Fausto, la descripción se reduce de esta manera:

$$
\begin{aligned}
& \text { Llequé a un alto, finalmente, } \\
& \text { ande va la paisanada, } \\
& \text { que era la última camada } \\
& \text { en la estiba de la gente. }
\end{aligned}
$$

24 En el Fausto:

No bien me había sentao rompió de golpe la banda que detrás de la baranda la habian acomodao. 
su propio miedo, su "espantada" a una hipotética espantada de caballo. (Momo, más sencillamente, ha confesado momentos antes que la irrupción de la orquesta le provocó una espantada similar: "Yo di una encoginada, que fue floja en gracia de Dios"):

Y ya también se corrió

una gerga y una manta,

que a estar allí se me espanta

el bayo, créamenlo. ${ }^{25}$

El decorado que Momo ve en escena es un "a moo de estrado", "que sería de un palacio". De acuerdo con las características de la ópera Safo. Anastasio, en la Carta, menciona sólo un monte. La sorpresa por el cambio de escena se expresa en ambos relatos indirectamente: para Momo el telón "desaparece" sin saber cómo ni por dónde, y en su lugar "había" al frente ese a modo de estrado. El gaucho de la Carta, dice su asombro en una exclamación, "velay", a la que sigue esta justificación:

Tras aquel mantón un monte había escondido que no lo había advertido por estar cáido el gergón. ${ }^{26}$

E) Los personajes: Los personajes femeninos, Desdémona y Safo, asombran a los narradores por el colorido de sus ropas y el brillo que despiden sus trajes a la luz de las candilejas. Momo ve a una mujer djicalada, con terciopelos, bordaduras de oro y dijes. La compara con Isabel II, reina de España, y con la Virgen del Rosario. ${ }^{27}$ A pesar de que Anastasio apenas describe los vestidos de Safo, advertimos la misma riqueza velazquiana de luces y colores:

25 Es casi literal la transcripción en el Fausto:

Y ya también se corrió

un lienzo grande, de modo. que a dentrar con flete y todo me aventa, créamelo. garita.

26 En Fausto, recuérdese la colorida descripción literaria del jardín de Mar-

27 El efecto cómico de confundir a un personaje de la escena con un personaje real se repite en la Carta cuando se confunde al mayor Sotelo con Otelo; y en el Fausto, cuando Laquna cree que ese nombre designa a un coronel que había conocido en la Banda Oriental cuando esa soldado. 
Otra moza apareció

de rebozo colorado, overo, grande y plateado. ${ }^{28}$

Desdémona, en el acto final de Otelo, se le aparece a Momo "vestida de blanco que parecía amortajada"; Anastasio el Pollo ve al coro de las griegas como "ensabanadas" o "fantasmería". Ambas protagonistas cantan acompañadas con el arpa. Momo cescribe el instrumento como "una guitarra muy grande". ${ }^{29}$ Anastasio, en la Carta, afirma:

Al rato se apareció

traindo en la mano una harpita

relumbrante $y$ doradita. ${ }^{30}$

Para la descripción de los personajes masculinos - excepto Oteloambos relatores utilizan el mismo tono despreocupado y palabras equivalentes. Para Momo, el padre de Desdémona es "un señor mayor"; para Anastasio en la Carta Faón es "un mozo flacón".

Momo debe salir del teatro para evitar un altercado. Hasta tal punto ha confundido realidad con fantasía que - como cuentan tantas anécdotas gauchescas- ha intervenićo en la acción teatral. También Anastasio el Pollo, al final de la Carta, se apresta a intervenir:

28 Aunque menos ajicalada, la Margarita del Fausto aparece con el mismo brillo transferido de las vestiduras a los cabellos y a la belleza de su piel:
¡Ah, don Laguna! Si viera
¡qué tubia! Créamelo:
creí que estaba viendo yo
alguna virgen de cera.
Vestido azul, medio alzao,
se apareció la muchacha:
pelo de oro como hilacha
de trigo recién cortao.
Blanca como una cuajada, y celeste la pollera.
Don Laguna si aquello era mirar a la Inmaculada.

Obsérvese que aquí, como en el relato de Momo, se compara a la protagonista con la Virgen.

29 En la edición citada, se aclara "apparently a harp".

30 En Fausto, Mefistófeles toca una guitarra y 
Yo ya me iba desnudando

porque soy güen nadador,

pa ofertarle mi favor

a la que se estaba augando.

Coincide, por último, el recurso cómico de deformar palabras en boca de Momo o de Anastasio. Cuando Momo pregunta el nombre del negro que aparece en escena, le responden que se llama Otelo. El nos transmite su versión alterada del nombre: Telo. El protagonista de la Carta de Anastasio el Pollo sobre el beneficio de la señora de la Gria, al hacerse leer el cartel que anuncia el beneficio, incurre en parecido error auditivo:

Que de mi mayor Sotelo un arria iban a largar. ${ }^{31}$

Por las fechas, ambos autores deben referirse al Otelo de Rossini estrenado en Europa en 18r9.

Si entre el relato de Momo y la Carta que es prefiguración del Fausto hallamos estas relaciones, mucho más profundas las encontramos entre el mismo relato y el Fausto definitivo. Para analizarlas debidamente vamos a distinguir en el episodio de Fernán Caballero y el poema de Del Campo cuatro planos superpuestos que se alternan o imbrican provocando efectos cómicos: A) El plano de lo que realmente ocurre en escena; es ćecir, lo que se representa, sus decorados, personajes y acción independientes de la visión del espectador que narra. B) El plano de lo que el narrador creyó ver u oír en escena y los sentimientos que provocaron en él esas confusiones o fantasías. En la confrontación entre este plano y el anterior asienta la mayor comicidad de los relatos. C) El plano de la expresión; es decir, cómo cuenta el narrador lo que ha sucedido realmente en escena o lo que él ha creído ver u oír. Entran nuevos elementos de comicidad. D) El plano de los interlocutores, que

31 Tiene el mismo valor la deformación de Gría en grulla. Al principio de la narración de Mcmo, la criada de la Gaviota le dice a Nicolás: "lleva ese ganso, al treato". Anastasio, en la Carta, reconoce el "treato de Carlón"; en el Fausto, "el tiatro de Colón". 
a su vez producen efectos cómicos al interpretar los sucesos. Solicitan explicaciones, interfieren y participan emotivamente del relato.

A) Lo que redmente ocurre en escena: El relato de Momo es sólo un episodio dentro de la economía total de La Gaviota. A Fernán Caballero no le interesa la acción de la ópera Otelo sino aquellas escenas de mayor importancia que sirven para confundir al ingenuo campesino. Esas escenas son las que tienen como figura central a Desdémona, que es el personaje de interés porque lo encarna María. Si en la segunda escena Otelo cobra alguna importancia es con relación a la muerte de María. En este plano existe pues una selección de elementos que determinan el primer impacto en el paisano: Desdémona está representada por María; María está vestida como una princesa; María llama padre a quien no lo es mientras su padre propio agoniza; un moro acuchilla a Maria. No se trata de una interpretación del rústico: esos sucesos ocurren así ante sus ojos. El efecto cómico nace de que el rústico no entienda que eso pueda ser una representación.

El Fausto, en cambio, cuenta detalladamente la ópera de Gounod. Es un poema completo y no un episodio dentro de un relato mayor. Resumir su contenido sería reproducir quizá el libreto de la ópera que el poeta tuvo en sus manos durante la creación del poema.

No obstante, hay también en el Fausto una selección. El personaje que más importa es Mefistófeles. Mefistófeles, es decir el diablo. pertenece a la realidad del gaucho; pero no a esa realidad casi física a que pertenece María con respecto a Momo. Es un ser existente en la realidad moral del gaucho. Tiene un valor inverso al de María. María es un ser real que se convierte en una Desdémona de fantasía. Mefistófeles es un ser de fantasía que se convierte en real, visible y palpable personaje teatral. Mientras en Momo, el efecto cómico en este plano se profundiza por la impostura de María, que se ha disfrazado y ha asumido otra personalidad, en el Fausto es de mayor calidad y aún más profundo: su temor inconsciente se objetiva en escena. La fantasía le juega una trampa a Momo, la redilidal a Anastasio en el Fausto.

B) Lo que el narrador cree ver u oir en escena y los sentimientos que provocaron en él esas confusiones y fantasias: Algunos elementos externos al drama que se representa conspiran contra ambos espectadores contribuyenco a la confusión que experimentan: la bajada y subida del telón, el cambio de decorados, el diálogo cantado y en idioma extran- 
jero. De ese modo, los sucesos de la escena aparecen rodeados de un clima extraño. Esos sucesos, además, carentes de la lógica común, se les presentan sin ilación alguna. Como ambos narradores no saben aceptar al teatro como teatro y no comprenden la urdimbre propia del género, ignoran la causalidad de la ficción escénica. Creen asistir a sucesos u ordenacios arbitrariamente por la casualidad, o manejados por fuerzas diabólicas. Por eso en el relato de Momo, cada personaje "allí se presenta", el demonio "había puesto una principesa"; "cuando menos se pensaba, entra un señor mayor"; la Gaviota "se puso a cantar", "sacó una guitarra" "que puso en el suelo", "de repente sale un moro", etcétera. $\mathrm{La}$ acción se narra sin la lógica interior que diferencia el teatro de la realidad. También en el Fausto "el doctor apareció y en público se quejó", en la taberna "se armó una reunión", don Valentín "se hallaba allí en la ocasión", "una iglesia apareció - en menos que canta un gallo", etcétera.

El descalabro lógico que supone ver sucesos sin un ordenamiento interior hace que ambos espectadores se expliquen de algún modo la razón de las mutaciones escénicas. Momo entiende que el cambio de traje de Desdémona se debe a "que le había mandado el general a la Gaviota que se quitase los arrumacos". En Fausto la desaparición de Margarita de la escena tiene motivos parecidos: "El Diablo entonces mandó - a la rubia que se juese".

Ambos relatores rebajan a su propio nivel el contenido de los dramas que ven, como intento de explicárselos. Hacen trivial el drama y así lo colocan cerca de sus propias naturalezas. Momo entiencle que la discusión de Desdémona con su padre se debe a una trapisonda de la Gaviota que quiere ser reconocida como hija por el general carlista. Este recurso se repite incesantemente en el Fausto. Es el mismo espíritu que reina en la escena de la taberna: Valentín "va a la guerra del Paraguay"; don Fausto invita a Margarita a bailar "un cielo"; el vals final es ordenado por el "bastonero borracho".

Tanto el rústico español como el gaucho argentino reaccionan afectivamente ante los sucesos que creen ver en escena: "Yo estaba cuajado", repite Momo. "Caramba - dije yo para mi chaleco-no quisiera estar yo en el pellejo de esa Gaviota". En Fausto, leemos a cada instante expresiones como éstas: "Nunca lo hubiera llamao - Viera sustazo, por Cristo"; "Persinese-que lo mesmito hice yo", "que yo a mis ojos sentí - dos lágtimas asomarse"; "Bajaron el cortinao - de lo que yo me alegté". 
C) El plano de la expresión: Los dos planos anteriores tienen referencia con el momento en que los rústicos están en el teatro. Pero ambos se encuentran en la necesidad de contar esos sucesos. Se esfuerzan por transmitir la experiencia. En primer lugar, se precaven contra ra incredulidad de sus oyentes. Momo manifiesta que no dice "naita mas que la purísima verdad". Su verdad es lo que creyó ver; en la ciudad "no se puede decir la verdad": un espectador se molesta por su intervención en favor de la verçad. Refuerza Momo su apelación a la confianza de sus interlocutores con gestos como éste: "lo vi con estos ojos que ha de comer la tierra, y puedo dar testimonio". En el Fausto, Anastasio tiene idéntica preocupación: "No crea que lo le miento: -Lo ha visto media ciudá"; "¿Qué rubia!... Créamelo"; o con expresión que es también un gesto: "-Mire; que me caiga muerto- si no es la pura verdá".

Acotaciones verbales, frases reforzativas, interrogaciones retóricas, que acompañan al relato, le confieren en ambos casos mayor viveza y espontaneidad y actúan sobre los oyentes creando una atmósfera propicia para la credulidad que se exige y que apenas se logra, tan extraordinarios son los sucesos que se cuentan, traspuestos como están a la realidad inmediata. Momo interrumpe a cada instante con recursos de este estilo: "¿Cristianos! Yo no sé de dónde salió tanta criatura", "Pero asómbrense ustedes"; "María Santísima y qué atolondro", "Saben ustedes quién era?" "¿Qué enojado!". "¿Caramba!"; "¡Vaya, será la mora por allá!"; "¿Qué no es capaz de inventar esa Gaviota!"; “¡Pero qué moro!".

Del mismo modo y con el mismo valor, Anastasio en el Fausto matiza su relato con exclamaciones similares: "Cállese amigo"; "Ahí verá por fin, cuñao"; "Cristo mío"; "Y no haberlo yo sentido"; "Viera al diablo"; "¿Hizo bien, no le parece?"; "Viera al diablo retorcerse - como culebra, aparcero"; "Qué quinta, Virgen bendita"; "Y sacó, Virgen bendita- viera qué cosa, amigazo".

D) El plano de :'os interlocutores: El relato de Momo y el Fausto se diferencian fundamentalmente de la Carla por la presencia de interlocutores que contribuyen a extremar el dramatismo de la narración. El lector de ambos relatos puede medir el "crescendo" afectivo de la participación de esos interlocutores en el suceso que se narra a través de las frecuentes y reiteradas expresiones de conmiseración. La madre o la abuela de Momo manifiestan: "¿Pero, de dónde salió tanto músiço?"; "¿Qué estás diciendo, Momo?"; "¿A qué te metiste en eso?"; "¿Un moro?"; "iJesús, María!"; "iVirgen del Carmen! ¿Era acaso el verdu- 
go?"; “¿Pero qué hicieron tantos como presentes estaban?”; “¿No hubo nadie que prendiese a ese desalmado?"; "¡Ay, qué dolor, Qué dolor!".

El paisano Laguna interviene con mayor frecuencia: "¿Doctor dice? Coronel — de la otra banda, amigazo"; "¿Y cómo no disparó?"; "¿Hizo bien, no le parece?"; "No era un dotor muy projundo - cómo se dejó engañar"; "Canejo, será verdad - ¿Sabe que se me hace cuento?"; "Qué dice, barbaridad - Cristo padre, setá cierto?"; "Qué buche, Dios soberano", etcétera.

Mientras Momo habla sus interlocutores, compenetrados del relato, se expresan con sollozos o se retuercen las manos de dolor. Laguna, al terminar el Fausto, pide el pañuelo a Anastasio para secarse la frente. También a él el relato lo ha conmovido hasta trasmudarlo.

A pesar de lo extenso de nuestro análisis, ninguna comparación resulta tan clara para mostrar los muy evidentes contactos entre el Fausto de Estanislao del Campo y el relato de Momo en La Gaviota de Fernán Caballero, como la lectura paralela de ambos textos. De ella surgirá claramente la similitud de temas, de ambientes, ce ordenamiento, de tratamiento del habla, de intención y de recursos humorísticos.

\section{VI}

Una consideración final. En los dos relatos, narrador e interlocutores invocan constantemente a Dios y a la Virgen como conjurando un peligro extraño. Advertimos en el relato de Momo una presencia constante de alguien que sin ser personaje trastrueca frecuentemente la realidad. Todo lo que el rústico no entiende es obra de esa presencia presentida. Está ella fundida con el clima de miedo que rodea a Momo desde el principio en esa ciudad donde "se le abren las carnes". 32 ¿Qué otro ser, si no el diablo, puede reinar para la reaccionaria Fernán Caballero en el Madrid de los liberales? ¿No inicia Momo su relato con la intención de que su madre y su abuela "admiren los juicios de Dios y le bendigan" por haber llegado él sano y salvo? ¿No es la Gaviota la maldita Gaviota?

Esa presencia ciabólica es la que hace que la orquesta suene "de repente, y sin que nadie se lo mandase", o que el telón desaparezca "sin saber ni cómo, ni por dónde". Momo lo aclara en este caso: "No parecía sino que el demonio había cargado con él". A la Gaviota de la

32. Con parecida expresión; manifiesta Martin. Fietro (Primera parte, canto III) el terror que despierta la llegada del malón: 
realidad "se la había llevado el demonio, y en su lugar había puesto una principesa".

La terrorífica aparición del moro es un poco la personificación de esa fuerza extraña. Negro y "con un puñal en la mano tamaño como machete", como pinta al demonio la tradición popular española y argentina, es un ser "feróstico" al que se lo compara con Mahoma, por muchos siglos demonio negro de España.

Mefistófeles, feo y con "un sable largote", es también la personoficación del demonio popular. Del Campo - no es éste poco mérito- ha convertido en personaje esa presencia invisible que el rústico español, y cualquier sensibilidad ingenua, descubre en el juego teatral. Sea magia o misterio, sólo una ley sobrenatural puede explicar esa alucinada visión de un mundo dentro del mundo, con leyes que la razón no comprende. Al transformar ese sentimiento oscuro en un personaje autónomo ha efectuado del Campo un pase de prestidigitación. El gaucho no ve alucinaciones, ve al demonio mismo. No se trata sólo, como en Momo, de confuncir fantasía con realidad; la fantasía se ha vuelto realidad, más auténtica que la cotidiana en cuanto ha realizado también ocultas esperanzas del hombre: ver y tocar lo inexplicable. La impresión del gaucho, y la que el poema nos trasmite, cobra así en del Campo valor universal y humano. Se ha superado el simple pintoresquismo regional de Fernán Caballero.

Western Reserve University

RuBÉN BENÍTEZ 
